\title{
Effect of the Applied Current Density on the Structural and Magnetic Properties of the Electrodeposited Cobalt-Nickel Alloy Thin Films
}

\author{
R. ÖZDEMIR*
}

Kilis 7 Aralık University, Vocational High School, Kilis, Turkey

\begin{abstract}
In this study, cobalt-nickel (Co-Ni) alloys were deposited electrochemically onto aluminum substrates under applied current densities of 103.8, 138.4, 173 and $207.6 \mathrm{~A} \mathrm{~m}^{-2}$. Influence of the applied current density on the structural and magnetic properties of the Co-Ni alloys was investigated. The bath for Co-Ni alloys deposition was composed of $0.08 \mathrm{moll}^{-1} \mathrm{CoSO}_{4} \cdot 7 \mathrm{H}_{2} \mathrm{O}, 0.2 \mathrm{moll}^{-1} \mathrm{NiCl}_{2} \cdot 6 \mathrm{H}_{2} \mathrm{O}, 0.1 \mathrm{moll}^{-1} \mathrm{NiSO}_{4} \cdot 6 \mathrm{H}_{2} \mathrm{O}$ and $0.25 \mathrm{moll}^{-1} \mathrm{H}_{3} \mathrm{BO}_{3}$. The electrochemical investigation of Co-Ni alloys was completed using cyclic voltammetry and galvanostatic studies. Inductively coupled plasma analysis has shown that the amount of the cobalt in the deposited alloy has decreased from $73.61 \%$ to $67.01 \%$ with the increase of the applied current density from 103.8 to $207.6 \mathrm{~A} \mathrm{~m}^{-2}$. According to the magnetic analysis results, the values of coercivity coefficient of the deposited Co-Ni alloys range between 115 and 150 Oe, confirming ferromagnetic behavior of the alloys. Experiment results indicate that magnetic and structural properties of the Co-Ni alloy deposits are greatly influenced by the applied current density in the electrodeposition system.
\end{abstract}

DOI: 10.12693/APhysPolA.132.770

PACS/topics: 81.05.Bx, 81.40.Rs, 82.45.Qr, 81.15.Pq

\section{Introduction}

Cobalt-nickel (Co-Ni) alloy coatings are important materials in science and engineering and have many applications due to their outstanding physical and chemical properties [1-2]. Recent studies have shown that $\mathrm{Co}-\mathrm{Ni}$ alloy coatings have good adhesion, heat conductivity, thermal stability, corrosion resistance, excellent mechanical, chemical and magnetic properties [3]. The Co-Ni alloys could be used as shape memory alloy and in soft magnetic films. Co-Ni alloy coatings are known as very good magnetic materials. These alloys exhibit a better permanent magnetic property compared to pure metals [4]. Additionally, magnetic composites based upon such alloys offer a possibility of modification of their magnetic properties (improved controllable coercivity and saturation magnetization) and thus can have many applications [4]. Co-Ni alloys are commonly used as typical magnetic materials, with applications in several fields [5].

Many different methods can be used for the fabrication of devices from magnetic materials, in both, micro and nano scales [6], such as sputtering [7], screen-printing and micro assembly [6]. Nevertheless, these methods are not effective for deposition of high quality, well controlled magnetic layers [6]. Electrodeposition is an easy and economic method for fabrication of the coatings with desirable characteristics [3-8].

Electrodeposition is also a popular technique for fabrication of magnetic films and alloys [9]. The use of electroplating to produce these kinds of alloys is attractive

\footnotetext{
*e-mail: rsmozdemir@gmail.com
}

because it is rapid, inexpensive, flexible, efficient and is easily extendable to high volumes of production in contrast with other methods, such as chemical vapor deposition and sputtering [10-12]. Use of electrochemical methods in deposition of metallic coatings is attractive due to a high degree of control, which can be performed by changing the experimental conditions [1]. Changes in the deposition conditions may result in a different composition, morphology or phase structure of the electrodeposited coatings. Properties of the deposited alloys are strongly dependent on the experimental parameters of electrodeposition, such as bath composition, deposition potential, $\mathrm{pH}$, stirring solution temperature, substrate, reference electrode and applied current [13, 14]. Magnetic properties of the Co-Ni coatings can be also controlled by changes of crystal structure, via changing conditions of deposition, such as current density [14].

In order to develop an understanding of the role of the applied current in electrodeposition, the effect of applied current density on the elemental composition, microstructure, morphology, electrochemical and magnetic properties and phases of the $\mathrm{Co}-\mathrm{Ni}$ coatings is investigated.

\section{Experimental}

Commercial aluminum plates with a surface area of $2.9 \times 10^{-4} \mathrm{~m}^{2}$ were used as substrates. The reason for selection of this type substrate is to easily stripe $\mathrm{Co}-\mathrm{Ni}$ coatings from substrate, to eliminate the influence of the substrate in further analyzes. The saturated calomel electrode (SCE) was used as the reference electrode and the platinum wire was used as the counter electrode. Before electrodeposition, aluminum substrates were polished and dipped into a $1 \mathrm{M} \mathrm{NaOH}$ at $70^{\circ} \mathrm{C}$ for $5 \mathrm{~min}$, 
to activate the surface of the substrates, and finally were rinsed in the clean water $(18 \mathrm{M} \Omega \mathrm{cm})$ and dehydrated with clean air. All thin film plating baths were prepared from high purity chemicals and twice distilled water.

Cyclic voltammetry (CV) experiments were carried out at $10 \mathrm{mV} \mathrm{s}^{-1}$ by scanning initially towards negative potentials. To determine appropriate potential and current values for deposition of Co-Ni alloys the applied potentials were recorded between $+0.6 \mathrm{~V}$ versus SCE (initial voltage) and $-1.6 \mathrm{~V}$ and completed at $+0.6 \mathrm{~V}$ versus $\mathrm{SCE}$, to show reaction of the substrate under the negative and positive polarisations.

Co-Ni alloys were deposited galvonostatically under varyed current values of $30,40,50$ and $60 \mathrm{~mA}$, corresponding to current densities of 103.8, 138.4, 173 and 207.6 $\mathrm{A} \mathrm{m}^{-2}$. A sulfate bath was used as electrolyte solution in a traditional glass cell. Composition of the bath consisted of cobalt sulphate $\left(\mathrm{CoSO}_{4} \cdot 7 \mathrm{H}_{2} \mathrm{O}\right) 0.08 \mathrm{Moll}^{-1}$, nickel sulphate $\left(\mathrm{NiSO}_{4} \cdot 6 \mathrm{H}_{2} \mathrm{O}\right) 0.10 \mathrm{Moll}^{-1}$, nickel chloride $\left(\mathrm{NiCl}_{2} \cdot 6 \mathrm{H}_{2} \mathrm{O}\right) 0.20 \mathrm{Moll}^{-1}$ and boric acid $\left(\mathrm{H}_{3} \mathrm{BO}_{3}\right)$ $0.25 \mathrm{Moll}^{-1}$. Solution $\mathrm{pH}$ was adjusted to 4.5 by $1 \mathrm{M} \mathrm{HCl}$ and $10 \% \mathrm{NaOH}$ solutions (Hanna Scientific pH-meter). Solution was stirred during deposition to maintain homogeneity. The temperature was kept constant at $50^{\circ} \mathrm{C}$.

After electrodeposition process, $\mathrm{Co}-\mathrm{Ni}$ coatings were stripped from aluminum substrate. All deposited alloys have a thicknesses of approximately $1 \mu \mathrm{m}$.

The crystallographic structure of Co-Ni alloys was analyzed with a Rigaku diffractometer. The X-ray analysis was performed at $30 \mathrm{~mA}$ and $40 \mathrm{kV}$ in $2 \theta$ range of $5-90^{\circ}$, using $\mathrm{Cu} \mathrm{K} \mathrm{K}_{\alpha}$ radiation, at the rate of $0.05^{\circ}, 2 \theta / 0.5 \mathrm{~s}$. Surface morphology of the samples were observed using a scanning electron microscope $(\mathrm{SEM})$ up to $\times 2500$ magnification. Inductively coupled plasma (ICP) analyses were performed to analyze elemental composition of the deposited films. The magnetic hysteresis loops of the samples were determined using a vibrating sample magnetometer. Magnetic measurements were performed at $300 \mathrm{~K}$, in applied magnetic field from -75 to $+75 \mathrm{kOe}$.

\section{Results and discussion}

Electrochemical characterization of the deposition bath was performed by cyclic voltammetry. Figure 1 shows cyclic voltammetry diagram of the Co-Ni deposition. The scans were initiated at open circuit potential of the baths. During potential scan towards negative direction, a rapid increase of the cathodic current was observed. Deposition potential of the $\mathrm{Co}-\mathrm{Ni}$ alloy started at $-0.76 \mathrm{~V}$ because of the current flow in the negative direction. The anodic process shows an anodic dissolution at $-0.61 \mathrm{~V}$ vs SCE. According to CV diagram, film dissolution appears under $-0.61 \mathrm{~V}$.

Figure 2 shows the XRD analysis patterns of the $\mathrm{Co}_{1-x} \mathrm{Ni}_{x}$ alloys electrodeposited from electrolytic bath. The XRD analysis shows that electrodeposited $\mathrm{Co}_{1-x} \mathrm{Ni}_{x}$ alloys have different crystal orientations. XRD peaks of the alloys display a preferred orientation along the (111), (200) and (220) planes. The XRD pattern of

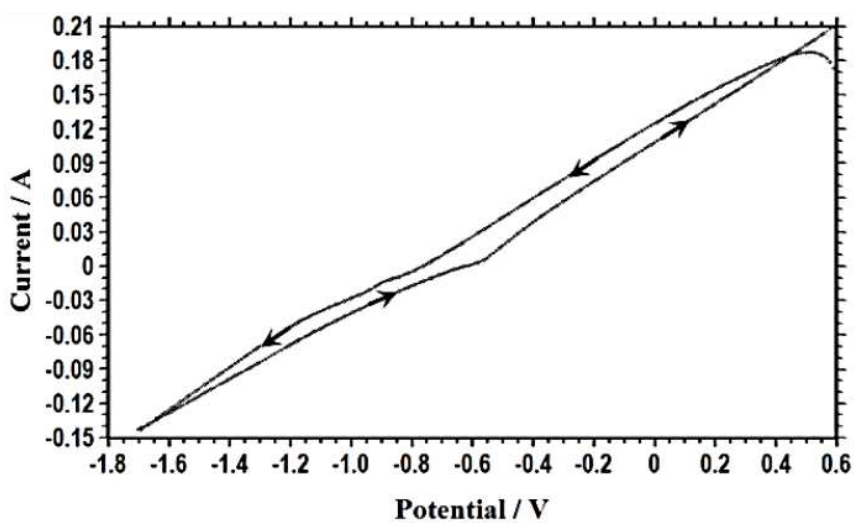

Fig. 1. Cyclic voltammogram for deposition of $\mathrm{Co}-\mathrm{Ni}$ alloy.

$\mathrm{Co}_{1-x} \mathrm{Ni}_{x}$ alloys shows a broad prominent peak at around $2 \theta=44.40^{\circ}$, corresponding to the (111) plane of the face centered cubic (fcc) phase of Co-Ni [14]. It is known that for Co-Ni alloys, mostly a fcc phase is observed for a $\mathrm{Ni}$ content higher than $25 \%$ in alloy [15]. Co-Ni alloys have a hcp phased crystalline structure if the $\mathrm{Ni}$ content is below $25 \%$. The observed fcc phase of the $\mathrm{Co}_{1-x} \mathrm{Ni}_{x}$ alloys is in conformity with the reported phase diagram of Co-Ni binary alloy [14-16].

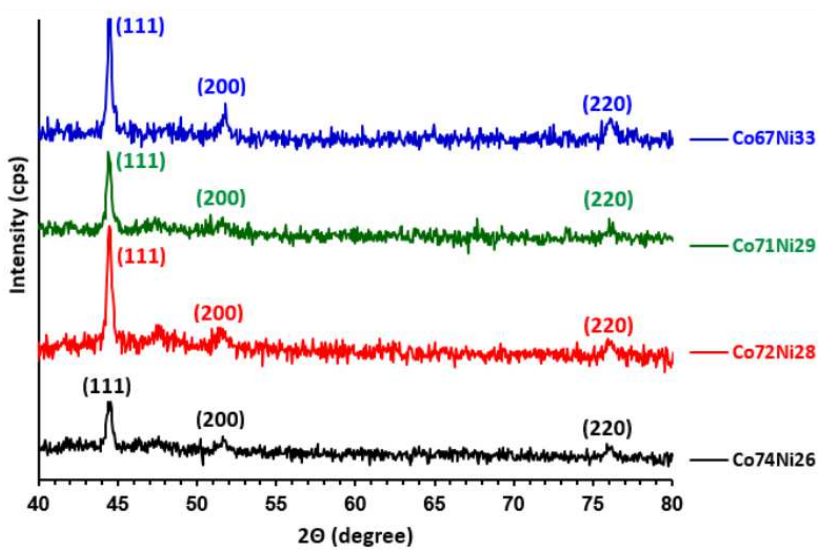

Fig. 2. XRD diagram of the $\mathrm{Co}_{1-x} \mathrm{Ni}_{x}$ alloy films, deposited at various applied currents.

Average grain size values of the alloys were calculated using the peak width at the half maximum $\beta$, using Scherer formula Eq. (1) [17-19]. Grain size values of the $\mathrm{Co}_{1-x} \mathrm{Ni}_{x}$ alloys as function of varied current and other XRD data are given in Table I.

$$
D=\frac{0.9 \lambda}{\beta \cos \theta} .
$$

Although all deposited films have similar phase structures, a great difference in grain size values of the alloys as a result of change in peak intensity and width were observed with change of applied current densities. As shown in Table I and Fig. 3, grain size increases from 222 to $381 \mathrm{~nm}$ with increase of the current density 
in the electrolyte from 103.8 to $207.6 \mathrm{~A} \mathrm{~m}^{-2}$. The increase of crystallite size with the increase of the applied current density was also observed in recent studies [20, 21].

TABLE I

XRD analysis data of the $\mathrm{Co}_{1-x} \mathrm{Ni}_{x}$ alloys deposited at various applied currents.

\begin{tabular}{c|c|c|c|c|c|c}
\hline \hline $\mathrm{SN}$ & $\begin{array}{c}2 \theta \\
\text { [deg.] }\end{array}$ & $\begin{array}{c}\mathrm{d} \\
{[\AA]}\end{array}$ & $\begin{array}{c}\text { Height } \\
{[\mathrm{cps}]}\end{array}$ & $\begin{array}{c}\text { FWHM } \\
{[\text { deg.] }}\end{array}$ & $\begin{array}{c}\text { Grain } \\
\text { size [nm] }\end{array}$ & $\begin{array}{c}\text { Current } \\
{\left[\mathrm{A} \mathrm{m}^{-2}\right]}\end{array}$ \\
\hline $\mathrm{Co}_{74} \mathrm{Ni}_{26}$ & 44.43 & 2.0373 & 193 & 0.40 & 222 & 103.8 \\
$\mathrm{Co}_{72} \mathrm{Ni}_{28}$ & 44.37 & 2.0400 & 511 & 0.30 & 298 & 138.4 \\
$\mathrm{Co}_{71} \mathrm{Ni}_{29}$ & 44.40 & 2.0388 & 361 & 0.28 & 325 & 173.0 \\
$\mathrm{Co}_{67} \mathrm{Ni}_{33}$ & 44.38 & 2.0394 & 557 & 0.23 & 381 & 207.6
\end{tabular}

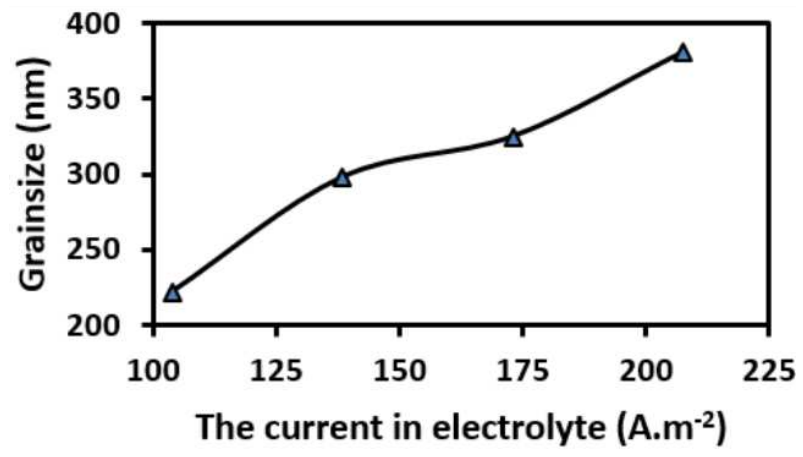

Fig. 3. The change of the grain size of the $\mathrm{Co}_{1-x} \mathrm{Ni}_{x}$ alloy films, deposited at various applied currents.

It is known that applied current has a significant effect on the crystalline structure and grain size of coated layers [22]. However, determination of this effect on the grain size of coatings is a very complex problem because of complexity of the electrodeposition mechanism. Electrochemical reactions, cluster growth mechanisms and charge transfer are the main mechanisms related to applied current and crystal growth of the coating [21]. It is suggested that for our experiments a stronger applied current had caused an increase in the energy of nucleus formation, which had caused bigger grain size of $\mathrm{Co}-\mathrm{Ni}$ coatings, as shown in Fig. 3.

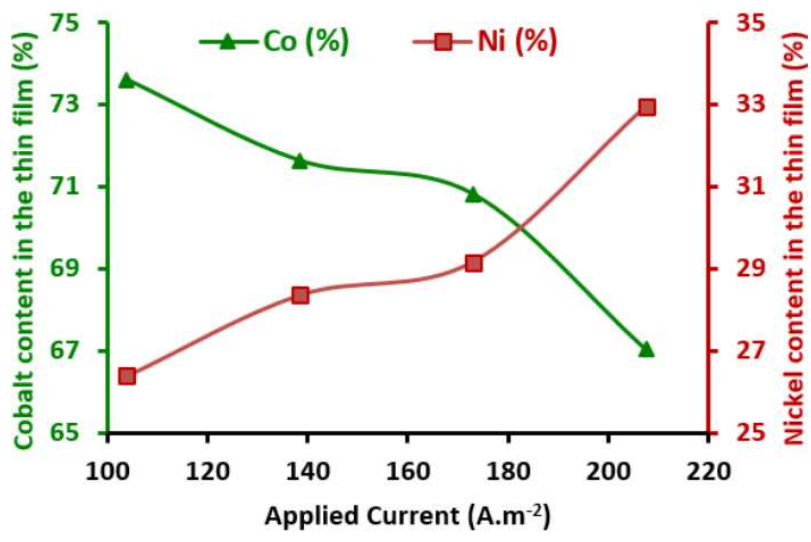

Fig. 4. Change of film content according to applied current.
Elemental composition of the alloys according to ICP analyzes is presented in Fig. 4. As seen in Fig. 4, cobalt content in the deposited alloy decreases from $73.61 \%$ to $67.01 \%$ with the increase of the current density from 103.8 to $207.6 \mathrm{~A} \mathrm{~m}^{-2}$. It must be pointed out that Co and $\mathrm{Ni}$ content was the same in the electrolytic solution. The change in the elemental composition of the alloy is completely caused by change in the electrodeposition parameter of applied current.

It is reported that anomalous codeposition can be either enhanced or suppressed by controlling experimental parameters of electrochemical depositions [23]. For codeposition of $\mathrm{Co}$ and $\mathrm{Ni}$ alloys, deposition of $\mathrm{Co}$ is mainly controlled by diffusion. On the other hand, deposition of $\mathrm{Ni}$ is controlled by activation [24]. Increase of the cathodic current density causes an increase in the cathodic overpotential, which leads to an increase in the electrode reaction [25]. As reported in recent studies, this overpotential causes an increase of nickel deposition and consequently a decrease in the cobalt content of deposited Co-Ni alloy [25].

Figure 5 shows the SEM images for electrodeposited $\mathrm{Co}_{1-x} \mathrm{Ni}_{x}$ alloy thin film coatings. According to the morphology studies, grain structure of the $\mathrm{Co}-\mathrm{Ni}$ alloys is affected by applied current density as was confirmed by XRD studies. Especially a significantly different surface morphology was observed in the alloy with the highest $\mathrm{Ni}$ content, see Fig. 5 d, which was probably caused by change in the grain size.

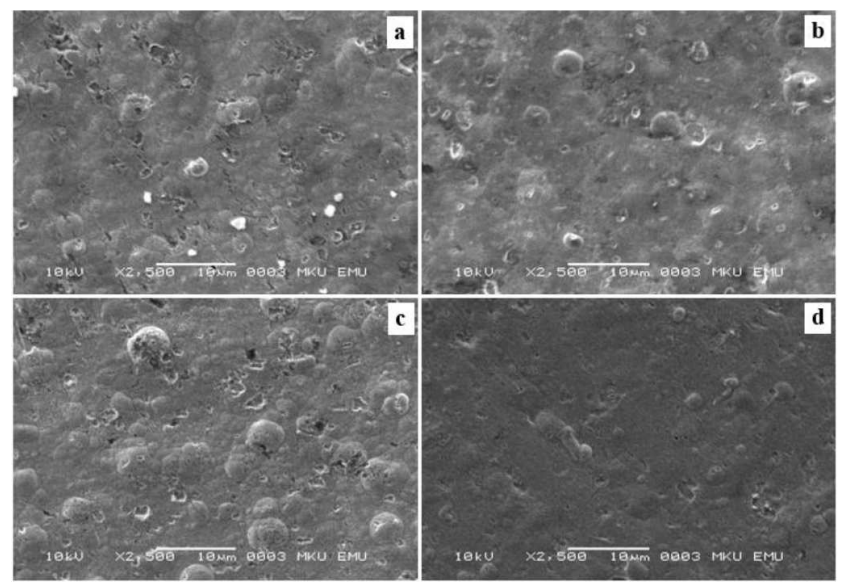

Fig. 5. SEM images of (a) $\mathrm{Co}_{74} \mathrm{Ni}_{26}$ alloy, (b) $\mathrm{Co}_{72} \mathrm{Ni}_{28}$ alloy, (c) $\mathrm{Co}_{71} \mathrm{Ni}_{29}$ alloy, (d) $\mathrm{Co}_{67} \mathrm{Ni}_{33}$ alloy.

The magnetic properties, i.e. the remanence magnetization $M_{\mathrm{r}}$, coercivity $H_{\mathrm{c}}$ and saturation magnetization $M_{\mathrm{s}}$ were obtained from the hysteresis loops for the deposited coatings at room temperature, as presented in Fig. $6 \mathrm{a}$ and $\mathrm{b}$. According to the results of magnetic analysis, the $H_{\mathrm{c}}$ values of the deposited $\mathrm{Co}-\mathrm{Ni}$ alloys have ranged between 115 and 150 Oe, confirming the ferromagnetic behavior of the alloys [26].

It is known that $H_{c}$ values of the magnetic materials are mainly effected by particle size and magneto 
crystalline anisotropy [27]. The decrease of the grain size in the magnetic material can cause a decrease in domain size, which results in lower $H_{\mathrm{c}}$ values [28].

Primarily a decrease of the $H_{\mathrm{c}}$ values with the increase of the $\mathrm{Ni}$ content is observed in our experiments. The change in the $H_{\mathrm{c}}$ is caused by the lower magnetic anisotropy and is also due to smaller magnetic moment of $\mathrm{Ni}^{2+}$ ion, compared to $\mathrm{Co}^{2+}$ ion $[29,30]$. The highest $H_{\mathrm{c}}$ of the sample with $71 \%$ Co content is probably caused by the additional effect of the large grain size.

As seen in Fig. 6, $M_{\mathrm{s}}$ decreases from 177.2 to $80.2 \mathrm{emu} / \mathrm{g}$ with the increase of $\mathrm{Ni}$ content in the alloy. It is suggested that decrease of $M_{\mathrm{s}}$ value is caused by the $M_{\mathrm{S}}$ value of the bulk Co $\left(1420 \mathrm{emu} / \mathrm{cm}^{3}\right)$ which is higher than that of bulk $\mathrm{Ni}\left(480 \mathrm{emu} / \mathrm{cm}^{3}\right)$ [31].
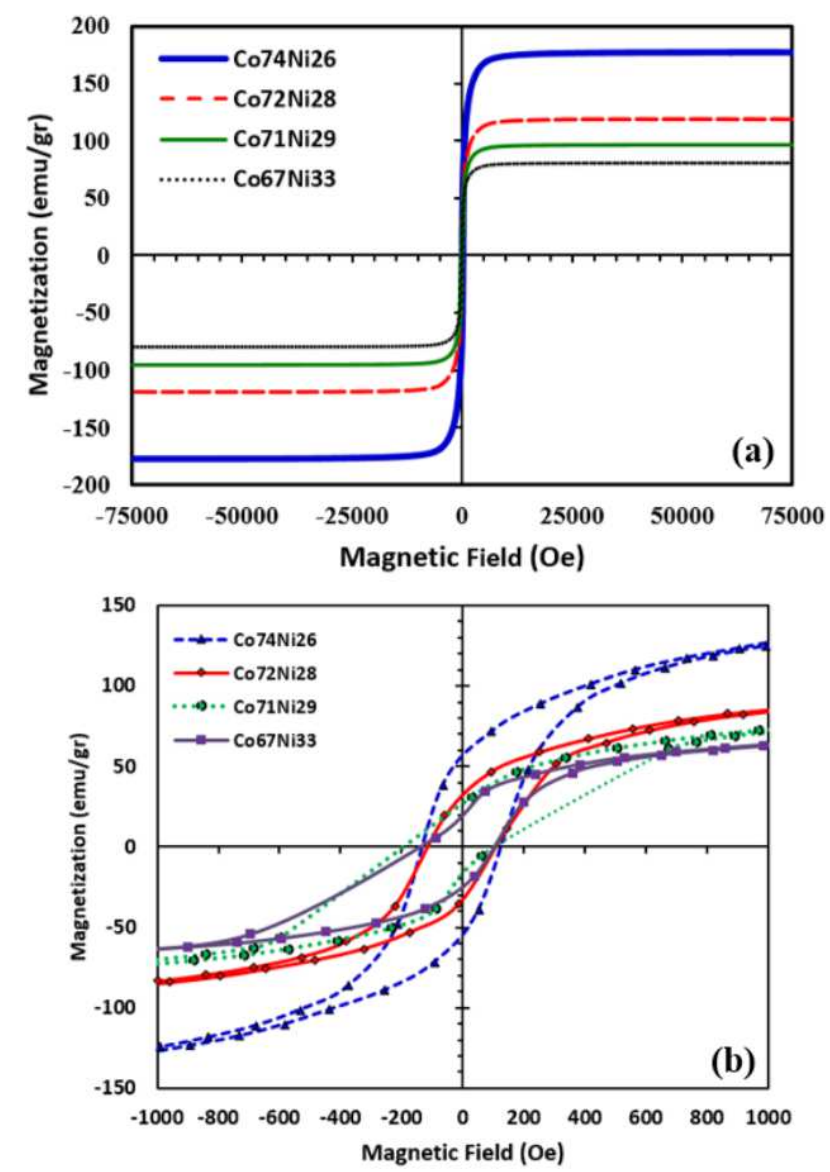

Fig. 6. Magnetization (emu/g) versus applied magnetic field (Oe) curves of $\mathrm{Co}_{1-x} \mathrm{Ni}_{x}$ alloys (a) between -75 and $75 \mathrm{kOe}$, (b) between -1 and $1 \mathrm{kOe}$.

Additionally, a decrease in the $M_{\mathrm{r}}$ values of the samples was observed with the increase of the $\mathrm{Ni}$ content in the alloy. The sample with lowest Co content of $67 \%$ has $M_{\mathrm{r}}$ value of $18 \mathrm{emu} / \mathrm{g}$, which was the lowest $M_{\mathrm{r}}$ value among all samples. The decreasing trend of $M_{\mathrm{s}}$ and $M_{\mathrm{r}}$ values with decrease of the Co content is due to higher magnetic anisotropy of Co compared with $\mathrm{Ni}$.
As was discussed above, $H_{\mathrm{c}}, M_{\mathrm{s}}$ and $M_{\mathrm{r}}$ values of the samples indicate that magnetic behavior of the deposited $\mathrm{Co}-\mathrm{Ni}$ alloys decreases with increase of the $\mathrm{Ni}$ ratio in the alloy. This is an expected result due to magnetic anisotropy and also bulk $M_{\mathrm{s}}$ value of the Co, which are higher than those of $\mathrm{Ni}$ [32]. It can be said that the increase in the Co content results in a stronger magnetic behavior of Co-Ni alloys.

\section{Conclusions}

In this study Co-Ni alloys were deposited electrochemically onto Al substrates. Effect of the applied current density on the structural and magnetic properties of the deposited alloys was investigated. According to analysis results, varied current density values had affected the deposited alloys. A significant change in grain size, elemental composition and magnetic behavior of the alloys was observed. Surface morphology and crystalline structure were also affected by the applied current. It is observed that with the increase of the applied current density, Ni content in the alloy is increased.

Analysis results for the deposited alloys indicate that coercivity, saturation magnetization and remanence magnetization values are strongly related to the elemental composition of the alloys, which can be controlled with applied current density. With the decrease in the Co content, the magnetic behavior of the alloy is decreased, as expected, due to higher magnetic anisotropy of the Co compared to $\mathrm{Ni}$.

\section{Acknowledgments}

This study has been supported by the Kilis 7 Aralık University Scientific Research Project, which is gratefully acknowledged (BAP-2014/02/LTP/05).

\section{References}

[1] R. Oriňáková, A. Oriňá, G. Vering, I. Talian, R.M. Smith, H.F. Arlinghaus, Thin Solid Films $\mathbf{5 1 6}$ 3045 (2008).

[2] I.H. Karahan, R. Özdemir, Appl. Surf. Sci. 318, 100 (2014).

[3] Yu.N. Bekish, S.K. Poznyak, L.S. Tsybulskaya, T.V. Gaevskaya, V.A. Kukareko, A.V. Mazanik, J. Electrochem. Soc. 161, D620 (2014).

[4] L. Tian, J. Xu, S. Xiao, Vacuum 86, 27 (2011).

[5] A. Dolati, M. Sababi, E. Nouri, M. Ghorbani, Mater. Chem. Phys. 102, 118 (2007).

[6] O. Ergeneman, K.M. Sivaraman, S. Pané, E. Pellicer, A. Teleki, A.M. Hirt, M.D. Baró, B.J. Nelson, Electrochim. Acta 56, 1399 (2011).

[7] J.V. Arenasa, L.A. Garcia, T. Treeratanaphitak, M. Pritzkera, R.L. Sánchez, R.C. Sierrac, Electrochim. Acta 65, 234 (2012).

[8] M.İ. Coşkun, İ.H. Karahan, T.D. Golden, Surf. Coat. Technol. 275, e1 (2015). 
[9] A. Karpuz, H. Kockara, M. Alper, Appl. Surf. Sci. 257, 3632 (2011).

[10] Y.D. Li, H. Jiang, D. Wang, H. Ge, Surf. Coat. Technol. 202, 4952 (2008).

[11] R. Özdemir, I.H. Karahan, Appl. Surf. Sci. 318, 314 (2014).

[12] S. Kirtay, Acta Phys. Pol. A 128, B-90 (2015).

[13] D. Golodnitsky, N.V. Gudin, G.A. Volyanuk, J. Electrochem. Soc. 147, 4156 (2000).

[14] A. Karpuz, H. Kockar, M. Alper, Appl. Surf. Sci. 258, 5046 (2012).

[15] S. Samardak, F. Nasirpouri, M. Nadi, E.V. Sukovatitsina, A.V. Ognev, L.A. Chebotkevich, S.V. Komogortsev, J. Magnetism Magnetic Mater. 383, 94 (2015).

[16] Sachil Sharma, N.S. Gajbhiye, R.S. Ningthoujam, J. Colloid Interface Sci. 351, 323 (2010).

[17] R. Ozdemir, I.H. Karahan, J. Optoelectron. Adv. Mater. 17, 14 (2015).

[18] M. Djamal, Ramli, Khairurrijal, F. Haryanto, Acta Phys. Pol. A 128, B-19 (2015).

[19] I.H. Karahan, R. Özdemir, Acta Phys. Pol. A 128, B-427 (2015).

[20] M.A. Kumar, S. Muthukumaran, J. Mater. Sci.: Mater. Electron. 24, 4050 (2013).
[21] R. Özdemir, I.H. Karahan, O. Karabulut, Metallurg. Mater. Trans. A 47A, 5609 (2016).

[22] U. Sarac, M.C. Baykul, J. Mater. Sci. Technol. 28, 1004 (2012)

[23] I.H. Karahan, Acta Phys. Pol. A 128, B-432 (2015).

[24] G. Qiao, T. Jing, N. Wang, Y. Gao, X. Zhao, J. Zhou, W. Wang, Electrochim. Acta 51, 85 (2005).

[25] Y. Li, H. Jiang, W. Huang, H. Tian, Appl. Surf. Sci. 254, 6865 (2008).

[26] W. Laslouni, M. Azzaz, Acta Phys. Pol. A 130, 112 (2016).

[27] V.K. Lakhani, B. Zhao, L. Wang, U.N. Trivedi, K.B. Modi, J. Alloys Compounds 509, 4861 (2011).

[28] A.M. Wahba, N.A. Ali, M.M. Eltabey, Mater. Chem. Phys. 146, 224 (2014).

[29] U.B. Sontu, V. Yelasani, V.R.R. Musugu, J. Magnetism Magnetic Mater. 374, 376 (2015).

[30] W. Laslouni, Z. Hamlati, M. Azzaz, Acta Phys Pol. A 128, B-190 (2015).

[31] A. Karpuza, H. Kockar, M. Alper, O. Karaagac, M. Hacismailoglu, Appl. Surf. Sci. 258, 4005 (2012).

[32] C. Fan, D.L. Piron, Electrochm. Acta 41, 1713 (1996). 